\title{
Maria João Martins, História da Criança em Portugal
}

José Pacheco dos Santos Júnior

\section{(2) OpenEdition}

\section{Journals}

Edição electrónica

URL: http://journals.openedition.org/medievalista/1384

DOI: 10.4000/medievalista.1384

ISSN: 1646-740X

\section{Editora}

Instituto de Estudos Medievais - FCSH-UNL

\section{Refêrencia eletrónica}

José Pacheco dos Santos Júnior, « Maria João Martins, História da Criança em Portugal », Medievalista [Online], 22 | 2017, posto online no dia 01 dezembro 2017, consultado o 23 setembro 2020. URL : http://journals.openedition.org/medievalista/1384 ; DOI : https://doi.org/10.4000/medievalista.1384

\section{(ब) $(1) \Theta$}

Mediavalista está licenciado com uma Licença Creative Commons - Atribuição-NãoComercial 4.0 Internacional. 
Título / Title: Recensão: MARTINS, Maria João - História da Criança em Portugal. Lisboa: Edições Parsifal, 2014 (200 pp.)

Autor(es) / Author(s): José Pacheco dos Santos Júnior

Universidade / University: Universidade de São Paulo

Faculdade e Departamento / Unidade de Investigação - Faculty and Department /

Research Center: Faculdade de Filosofia, Letras e Ciências Humanas

Código Postal / Postcode: 05508-000

Cidade / City: São Paulo

País / Country: Brasil

Email Institucional / Institutional email: josepsjunior@usp.br

Fonte: Medievalista [Em linha]. Direc. Bernardo Vasconcelos e Sousa. Lisboa: IEM.

Disponível em:

http://www2.fcsh.unl.pt/iem/medievalista/MEDIEVALISTA22/junior2210.html

ISSN: 1646-740X

Data de recepção do texto / Received for publication: 10 de Outubro de 2016 


\section{Recensão: MARTINS, Maria J oão - História da Criança em Portugal. Lisboa: Edições Parsifal, 2014 (200 pp.)} José Pacheco dos Santos Júnior

\section{O itinerário de um clássico: L'Enfant et la Vie familiale sous l'Ancien Régime}

No alvorecer da década de 1960, em Paris, alastravam rumores de que um importador de bananas defendia novas ideias sobre a história da infância e da família no Antigo Regime. Ele se chamava Philippe Ariès e acabara de publicar um livro: L'Enfant et la Vie familiale sous l'Ancien Régime, pela Plon. Mas afinal, quem foi esse “investigador solitário" ${ }^{1}$ que ousou desafiar a hegemonia de uma tradição historiográfica consolidada, como o reino da História Econômica, ao apresentar uma obra com metodologia, objetos e fontes tão atípicos? Formado em História pela Sorbonne, e isolado do universo acadêmico, já que optou por ser um "historiador de domingo" e trabalhar num instituto especializado em frutas tropicais ${ }^{2}$, Ariès escreveu três obras ${ }^{3}$ que ficaram à penumbra dos grandes debates realizados no período. Seria o nefasto resultado dos poucos gráficos e mapas de suas obras? De qualquer forma, foi essa a justificativa que o autor recebeu ao submeter para apreciação um de seus livros e ser negado pelos "herdeiros avarentos”, como descreve o próprio autor, de uma equipe editorial tradicional.

Mergulhado num ostracismo abissal, submerso no silêncio dos historiadores profissionais, incluindo os dos Annales, Ariès ascende-se à superfície em 1964, quando Jean-Louis Flandrin publica Enfance et sociétét: um artigo nos Annales ESC dedicado à

\footnotetext{
${ }^{1}$ ARIÈS, Philippe - Um historiador diletante. Rio de Janeiro: Bertrand Brasil, 1994, p. 10.

${ }^{2}$ FARIA, Sheila de Castro - "Philippe Ariès". in LOPES, Marcos Antônio; MUNHOZ, Sidnei J. (Org.) Historiadores de nosso tempo. São Paulo: Alameda, 2010, p. 251.

${ }^{3}$ ARIÈS, Philippe - Les traditions sociales dans les pays de France. Paris : Les Éditions de la nouvelle France, 1943; ARIÈS, Philippe - Histoire des populations françaises et de leurs attitudes devant la vie depuis le XVIIIe siècle. Paris : Self, 1948; ARIÈS, Philippe - Le Temps de l'Histoire. Paris : Éditions du Rocher, 1954.

${ }^{4}$ FLANDRIN, Jean-Louis - "Enfance et société". Annales. Économies, Sociétés, Civilisations, 19e année 2 (1964), pp. 322-329.
} 
análise de L'Enfant et la Vie familiale sous l'Ancien Régime, sua quarta obra, publicada em $1960^{5}$. Valendo-se de fontes diversas e até exóticas para o cenário historiográfico coevo e influenciado por sua esposa, uma apreciadora da História da Arte, Ariès pesquisou durante dez anos, entre 1950 e 1960, a criança e a vida familiar no Antigo Regime, amparando-se numa documentação que, como ímã, o atraía: as imagens.

Após ter descoberto as coleções de gravuras da Biblioteca Nacional, quando já havia terminado l'Histoire des populations e Temps de l'Histoire, Ariès foi motivado a escrever uma história do vestuário. Após uma primeira investigação, o pesquisador havia notado que a investigação demandaria um trabalho preparatório de datação e tipologia muito minucioso e demorado. Recusando um recorte cronológico curto, que para ele seria desinteressante por não cobrir mudanças culturais dignas de nota, tal projeto não foi efetivado $^{6}$. Contudo, uma semente havia sido lançada, Ariès, em suas primeiras explorações imagéticas, e instigado pelo interesse que portava há muito tempo pelas transformações contemporâneas dos modelos familiares, ficou impressionado com as representações e vestimentas das crianças em tempos passados. Eis que se concretiza, nos desejos do historiador, uma oscilação de interesse temático: da história do vestuário à história da criança.

As inquietações de seu tempo acerca da condição familiar na França do Pós-Guerra tiveram peso salutar na escolha de seus novos objetos de estudo. Percebendo que os meios católicos e conservadores davam como certo o declínio da família a partir da Revolução Francesa ${ }^{7}$, Ariès, diante dos fatos da vida cotidiana, notava justamente 0 contrário, a força e a consolidação da família ${ }^{8}$. A princípio, a primeira edição de l'Enfant ${ }^{9}$, publicada em 1960, foi bem recebida pelos historiadores: o livro chegou no

\footnotetext{
${ }^{5}$ A edição inglesa de L'Enfant et la Vie familiale sous l'Ancien Régime foi lançada em 1962 com o belo título, ainda que errado (na opinião de Ariès): Centuries of Childhood.

${ }^{6}$ ARIÈS, Philippe - Um historiador diletante, p. 132.

7 O enfraquecimento da autoridade paterna, a limitação da liberdade dos testamentos, a divisão do patrimônio, o direito ao divórcio e o novo casamento. ARIÈS, Philippe - Um historiador diletante, p. 133.

${ }^{8}$ ARIÈS, Philippe - Um historiador diletante, p. 133.

${ }^{9}$ Peter Burke lembra que a primeira edição do livro de Ariès continha vinte e seis pinturas, incluindo retratos feitos por Hans Holbein e Philippe de Champaigne e pinturas de gênero de Jan Steen e dos irmãos Le Nain, embora muitas outras imagens fossem discutidas no texto, as quais os editores não se sentiram em condições de incluir na obra. Entre os argumentos que Ariès usou com referência a essas fontes visuais está o da falta de segregação por idade no Antigo Regime, ilustrada por uma cena de uma taverna
}

Medievalista online $\mathrm{N}^{\circ} 22$ | Julho - Dezembro 2017 ( ) IEM - Instituto de Estudos Medievais 3 www2.fcsh.unl.pt/iem/medievalista 
momento em que o centro de interesse dos Annales e da École des Hautes Études se deslocava da esfera socioeconômica e demográfica para a da história das mentalidades. A família foi um dos primeiros temas da nova problemática. A segunda edição, em 1973, encontrou público maior e mais variado de psicólogos, médicos, sociólogos, assistentes sociais, etc. ${ }^{10}$ Tendo em vista a escassa bibliografia sobre o tema, alguns historiadores, incluindo medievalistas como Jacques Le Goff, assimilaram as teses de Ariès com entusiasmo, utilizando as ideias deste estudioso como inspiração ${ }^{11}$.

Ancorando-se na iconografia consultada, Philippe Ariès sintetiza sua tese ao defender a ausência de um "sentimento de infância" 12 na sociedade do Ocidente medieval. Para o autor, até por volta do século XII, a arte da Idade Média desconhecia a infância ou não tentava representá-la: “é mais provável que não houvesse lugar para a infância nesse mundo"13. Quando representadas artisticamente, as crianças estavam fadadas às mesmas indumentárias e caracteres dos adultos, contudo, em escala e estatura menor, adultos em miniatura. A alteração desse cenário inicia-se somente no século XIII com a "descoberta da infância”. Ariès destaca que essa evolução pode ser acompanhada na história da arte e na iconografia dos séculos XV e XVI. Ainda de acordo com ele, "os sinais de seu desenvolvimento tornaram-se particularmente numerosos e significativos a partir do

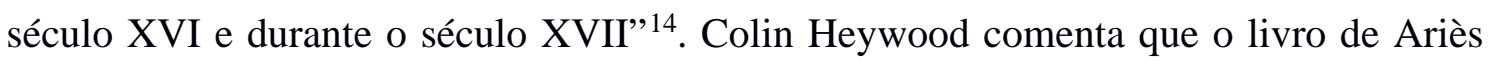
foi recebido com muito mais simpatia entre psicólogos e sociólogos que, na verdade, tiveram uma inclinação preocupante a tratá-lo como um "relato histórico", em vez de considerá-lo como uma tese bastante controversa. Judith Ennew observou que todos os sociólogos a ele retornam “assim como às Escrituras”15.

no século XVII na qual crianças e adultos se misturam. BURKE, Peter - Testemunha ocular: História e Imagem. Trad. Vera Maria X. dos Santos. Bauru: Edusc, 2004, p. 130.

${ }^{10}$ ARIÈS, Philippe - Um historiador diletante, pp. 135-136.

${ }^{11}$ Confira-se HEYWOOD, Colin - Uma história da infância: da Idade Média à época contemporânea no Ocidente. Trad. Roberto C. Costa. Porto Alegre: Artmed, 2004.

${ }^{12}$ Ariès defende a ideia de que na sociedade medieval o sentimento de infância não existia, o que para ele não quer dizer que as crianças fossem "negligenciadas, abandonadas ou desprezadas”. Segundo o autor, “o sentimento de infância não significa o mesmo que afeição pelas crianças: corresponde à consciência da particularidade infantil, essa particularidade que distingue essencialmente a criança do adulto, mesmo jovem”. ARIÈS, Philippe - História Social da Criança e da Família. $2^{\text {a }}$ ed. Trad. Dora Flaksman. Rio de Janeiro: LTC, 1981, p. 99.

${ }^{13}$ ARIÈS, Philippe - História Social da Criança e da Família, p. 17.

${ }^{14}$ ARIÈS, Philippe - História Social da Criança e da Família, p. 28.

${ }^{15}$ HEYWOOD, Colin - Uma história da infância, p. 24; Confira-se HEYWOOD, Colin - "Centuries of Childhood: an anniversary - and an epitaph?”. Journal of the History of Childhood and Youth, vol. 3, 3 (Fall 2010), pp. 341-365.

Medievalista online $\mathrm{N}^{\circ} 22$ | Julho - Dezembro 2017 ( ) IEM - Instituto de Estudos Medievais 4 www2.fcsh.unl.pt/iem/medievalista 
Em suma, a tese da ausência do sentimento de infância na Idade Média acendeu o fogo da crítica. Adrian Wilson, um dos críticos mais ácidos dos métodos de Ariès, ironizou, em seu famoso artigo "The infancy of the History of Childhood: an appraisal of Philippe Ariès”, ao declarar que talvez não seja surpreendente a ingenuidade com que a obra foi utilizada por sociólogos e psicólogos, mas os historiadores deveriam ter sido mais cautelosos ${ }^{16}$. Deste modo, é impossível tocar em L'Enfant et la Vie familiale sous l'Ancien Régime sem apresentar o debate, a discussão e algumas das repercussões que este livro irradia para a historiografia contemporânea, ainda que este seja, na opinião de Patrick Ryan, a obra mais criticada quando o escopo é a história da infância ${ }^{17}$. Deste modo, como lembra Heywood, apesar das fragilidades existentes, a pesquisa pioneira desse historiador francês propiciou o desenvolvimento de inúmeros estudos que colocaram no centro de suas indagações se no medievo houve "realmente uma consciência da infância, os períodos fundamentais na 'descoberta da infância', a natureza das relações entre pais e filhos nos diversos períodos e o papel das escolas, apenas para citar alguns” ${ }^{18}$.

Em 1964, quatro anos após a publicação da primeira edição, Jean-Louis Flandrin admitia, em artigo publicado nos Annales ESC, que na presença do trabalho de Philippe Ariès, dois sentimentos o invadiam contraditoriamente: admiração e inquietude ${ }^{19}$. Flandrin preocupou-se com a falta de comprovação empírica consistente no livro sobre a criança e vida familiar no Antigo Regime. Em cinco décadas não foram poucas as críticas atribuídas a Áries, principalmente quando se trata de suas considerações acerca da ausência do sentimento de infância na Idade Média, baseadas em sua análise das fontes iconográficas. Duas críticas de caráter geral são promovidas por Peter Burke: em primeiro lugar, Ariès é acusado de negligenciar a história das mudanças nas convenções de representação. Além disso, Ariès, como aponta Burke, ficou impressionado pela ausência de crianças na gênese da arte medieval e explicou essa ausência em termos de uma geral falta de interesse por crianças, ou mais precisamente pela infância. Por outro

\footnotetext{
${ }^{16}$ WILSON, Adrian - "The infancy of the History of Childhood: an appraisal of Philippe Ariès". History and Theory, vol. 19, 2 (February 1980), p. 153.

${ }^{17}$ RYAN, Patrick J. - "How new is the 'new' social study of childhood? The myth of a paradigm shift". Journal of Interdisciplinary History, vol. 38, 4 (Spring 2008), p. 566.

${ }^{18}$ HEYWOOD, Colin - Uma história da infância, p. 13.

${ }^{19}$ FLANDRIN, Jean-Louis - O Sexo e o Ocidente: evolução das atitudes e dos comportamentos. Trad. Jean Progin. São Paulo: Brasiliense, 1988. Originalmente publicado em: FLANDRIN, Jean-Louis “Enfance et société”. Annales. Économies, Sociétés, Civilisations, 19e année 2 (1964), p. 326.
} 
lado, Burke ainda revela que uma investigação posterior e mais detalhada do assunto demonstrou que as primeiras imagens medievais, na verdade, mostraram "um real interesse pela infância como tal”20. Assim, Ariès tem sido criticado de maneira incisiva por, supostamente, não compreender os códigos visuais provenientes do advento da Idade Média, como também "subestimar as funções ou os usos das imagens"21. No mesmo sentido, Heywood averigua que Ariès “parece pensar que o artista pinta aquilo que todos veem, ignorando todas as questões complexas relacionadas à forma como a realidade é mediada na arte”22.

A sociedade medieval portuguesa, por exemplo, objeto de estudo de Ana Maria Oliveira, não só atribuiu à criança uma decisiva importância no conjunto das idades da vida, como a considerou "suscetível de ser lexicalmente diferenciada e objeto de teorização e normalização jurídica, de forma a adequar o conceito às realidades e vivências sociais que, desde o século XII, tiveram nos jovens um decisivo fator de transformação e inovação"23.

Ao longo das cinco décadas da publicação de L'Enfant et la Vie familiale sous l'Ancien Régime não é de se estranhar que os debates entre os historiadores reflitam discussões corriqueiras, como notou Stearns, que muitas vezes "geram mais calor que luz"24. Philippe Ariès, consciente disso, declara durante uma autodefesa no prefácio da segunda edição de sua obra, treze anos depois: "um livro tem sua vida própria, e rapidamente escapa das mãos de seu autor para pertencer a um público nem sempre conforme ao que o autor previra” ${ }^{25}$. Abrindo timidamente os caminhos para a Nouvelle Histoire, que ganharia vigor a partir da década de 1970, Ariès, a sua obra e o debate que acenderam ajudaram a esboçar, voluntária ou involuntariamente, um novo campo de estudos para a literatura histórica: a história social da criança ou uma história cultural da infância.

\footnotetext{
${ }^{20}$ BURKE, Peter - Testemunha ocular, p. 131.

${ }^{21}$ BURKE, Peter - Testemunha ocular, p. 132.

${ }^{22}$ HEYWOOD, Colin - Uma história da infância, p. 25.

23 OLIVEIRA, Ana Maria T. S. R. - A Criança na Sociedade Medieval Portuguesa: modelos e comportamentos. Lisboa: Faculdade de Ciências Sociais e Humanas da Universidade Nova de Lisboa, 2004. Tese de Doutoramento, p. 39. Publicada com o título A Criança na Sociedade Medieval Portuguesa. Lisboa: Editorial Teorema, 2007.

${ }^{24}$ STEARNS, Peter N. - A infância. Trad. Mirna Pinsky. São Paulo: Contexto, 2006, p. 80.

${ }^{25}$ ARIÈS, Philippe - História Social da Criança e da Família, p. xi.
} 


\section{Um singelo e novo itinerário para a História da Criança no Velho Mundo}

Nesse contexto de abertura e expansão da historiografia mundial focada nos pequenos, encontra-se a obra História da Criança em Portugal (Edições Parsifal, 2014), da licenciada em História e jornalista Maria João Martins: autora de Mulheres Portuguesas: Divas, Santas e Demónios; Paraíso Triste: o Quotidiano em Lisboa durante a II Guerra Mundial, ambos de 1994, Luanda, Invenção de uma Capital (2014) e obras ficcionais a exemplo de Escola de Validos (2007) e Como o Ar que Respiras (2011); História da Criança em Portugal é fruto de sua "curiosidade insaciável” (p. 197) - no dizer da própria pesquisadora - por temas ligados ao cotidiano em distintas temporalidades.

O ponto de partida da incursão empreendida por Martins aos inúmeros universos infantis lusos - remotos e contemporâneos - inicia-se, numa seção de abertura intitulada “nota introdutória” (p. 11), com a reflexão acerca do papel da criança na família e na comunidade portuguesa. Para isso, o modo como se festeja o Natal, no tempo presente, incita a autora a buscar no passado as respostas de que precisa para solucionar a problemática imposta, que, logo em seguida, é resolvida e rapidamente apresentada ao leitor. O século XIX, que Martins classifica como o "Século de Alice” (em homenagem à personagem Alice de Alice no País das Maravilhas, de Lewis Carroll), recebe da autora o marco fundador para a invenção de um novo modo de ver e conceber as festividades natalinas, mais do que isso, como o nível de consumo - e a influência da industrialização - acelera-se e direciona-se ao público infantil, alterando seu modo de comemoração, em detrimento do sentimento religioso que embrionariamente havia lhes dado sentido. Na sequência, partindo da Idade Média (séculos XII-XV), título e recorte temporal do primeiro capítulo, as demais divisões do livro seguem uma articulação linear do processo histórico, notabilizada nos capítulos subsequentes: Antigo Regime (séculos XVI-XVIII), O século de Alice (1810-1910), República e Estado Novo (19101974) e O menino do cravo e seus filhos (de 1974 aos nossos dias).

Afinada com a tese de Ariès, a autora destaca que na Idade Média, em específico, “assim que a criança adquiria certa autonomia na linguagem, no desempenhar das suas funções mais elementares, tais como vestir-se e alimentar-se, era de imediato inserida no modo de vida dos adultos” (p. 30). Além disso, mesmo levando-se em consideração 
que no conjunto da obra há o predomínio sobre as particularidades das vidas das crianças da realeza lusa e dos pequenos fidalgos, consequência inclusive da quantidade de fontes que existem sobre esses sujeitos - e que foram preservadas —, Martins consegue, com louvor, tocar nas histórias das crianças pobres, aquelas que circulavam livremente pelas ruas das cidades medievais, que labutavam nos campos, oficinas artesanais e ambientes domésticos, que foram abandonadas - por inúmeros e complexos motivos - nas rodas dos expostos das Santas Casas da Misericórdia do Velho e do Novo Mundo a partir do Antigo Regime, que se divertiam com os brinquedos que compravam ou forjavam com os mais variados artefatos.

As representações, cultura material e o ensino destinados às plurais infâncias portuguesas também se fizeram presentes na reflexão da autora: a divisão etária conceitual predominante na Idade Média, o universo lúdico no Antigo Regime, a moda e literatura infantis no século XIX, as dimensões e o acesso à educação nos distintos momentos da história de Portugal; as nuances da infância no século XX sob o regime salazarista, o poder da mídia e da indústria de brinquedos para a conformação de uma nova relação entre a criança e a família também estão contidos na análise de Maria João Martins.

Das páginas de História da Criança em Portugal sobressai uma proposta pautada essencialmente na escala da micro-história aliada à essência da tradição historiográfica derivada da História da Vida Privada. Empreendimento este bem-sucedido, mesmo com a tímida explanação de alguns tópicos, o que leva a publicação a transitar pelas mãos de diferentes leitores com propósitos múltiplos. Tratando da vida no medievo, Martins escreve que "numa época em que a esperança média de vida era curta e a mortalidade infantil implacável, a infância era breve como um amor de Verão” (p. 19), este trecho particular desnuda uma das principais peculiaridades da linguagem utilizada pela autora portuguesa: o tom literário - às vezes romanceado - um tanto caro aos leitores acostumados à “cientificidade” - às vezes não decodificável ao grande público da linguagem historiográfica acadêmica. Sua experiência como jornalista e escritora ficcional lhe instrumentalizou com uma narrativa objetiva e aparentemente acessível, dando corpo à produção historiográfica que nas últimas décadas tem contemplado não

Medievalista online № 22 | Julho - Dezembro 2017 ๑ IEM - Instituto de Estudos Medievais 8 www2.fcsh.unl.pt/iem/medievalista 
apenas a academia, mas um público muito maior, ávido por apreciar as entrelinhas da História.

Ricamente ilustrado, o livro não malogra pela inexistência de documentação imagética. No entanto, para além de ilustrar a obra, se apresentando como meras coadjuvantes, tais fontes poderiam ter sido exploradas e dialogadas com a narrativa de maneira mais enérgica. Já a ousada tentativa de sintetizar quase nove séculos, condensados em duzentas páginas em uma única obra, não deixa dúvidas quanto ao principal traço da publicação: uma estrutura enciclopédica e fundamentalmente linear. Contudo, isso não inviabilizou o notável esforço da autora em mapear e usar uma diversidade de documentos (anais da realeza lusa, iconografia, cartas, literatura, propagandas, legislação, etc.), além de uma consistente bibliografia geral e específica.

Apesar da ausência de um capítulo de conclusão e das limitações pertencentes a qualquer trabalho dessa natureza, nada tira o êxito de História da Criança em Portugal, livro que veio somar forças à historiografia lusófona focada nos pequenos, seja sobre as suas experiências ou sobre as representações que lhes foram destinadas, internalizadas e (re)codificadas pelas próprias crianças ao longo dos séculos.

A porta que Ariès ajudou a abrir, com todos os entraves e profusão de críticas, elencadas neste texto, ainda permanece aberta, disposta a permitir a entrada de novos estudos que lancem luz à História da Criança no Ocidente. A singela contribuição de Maria João Martins, sem dúvidas, é tributária de uma historiografia que se erigiu após um longo caminho de pedras e que hoje se permite, merecidamente, desfrutar de uma miríade de documentos, olhares e linguagens, como também direcionar-se a um público muito mais amplo, diversificado e igualmente apreciador dos estudos históricos. 


\section{COMO CITAR ESTE ARTIGO}

\section{Referência electrónica:}

SANTOS JÚNIOR, José Pacheco dos - "Recensão: MARTINS, Maria João - História da Criança em Portugal. Lisboa: Edições Parsifal, 2014 (200 pp.)”. Medievalista 22 (Julho-Dezembro 2017). [Em linha] [Consultado dd.mm.aaaa]. Disponível em http://www2.fcsh.unl.pt/iem/medievalista/MEDIEVALISTA22/junior2210.html ISSN 1646-740X.

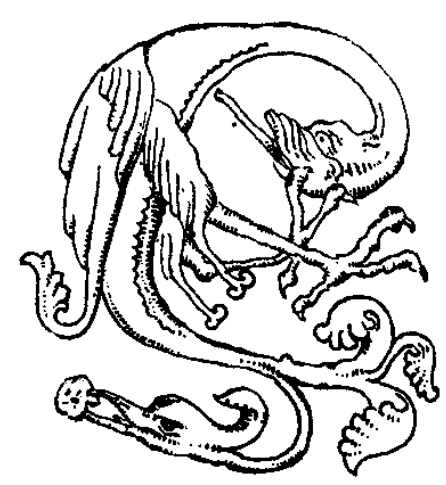

